\title{
Determinants of the outcomes of patients with cancer infected with SARS-CoV-2: results from the Gustave Roussy cohort
}

\author{
Laurence Albiges ${ }^{1}$, Stéphanie Foulon², Arnaud Bayle1, Bertrand Gachot ${ }^{3}$, Fanny Pommeret ${ }^{1,3}$, \\ Christophe Willekens ${ }^{4}$, Annabelle Stoclin ${ }^{3}$, Mansouria Merad ${ }^{3}$, Frank Griscelli ${ }^{5}$, Ludovic Lacroix ${ }^{5}$, \\ Florence Netzer ${ }^{6}$, Thomas Hueso ${ }^{4}$, Corinne Balleyguier7, Samy Ammari', Emeline Colomba', \\ Giulia Baciarello', Audrey Perret ${ }^{1}$, Antoine Hollebecque ${ }^{1,8}$, Julien Hadoux ${ }^{7}$, Jean-Marie Michot ${ }^{8}$, \\ Nathalie Chaput ${ }^{4}{ }^{4}$, Veronique Saada5, Mathilde Hauchecorne', Jean-Baptiste Micol ${ }^{4}$, \\ Roger Sun ${ }^{\circledR}{ }^{9}$, Dominique Valteau-Couanet ${ }^{10}$, Fabrice André ${ }^{1}{ }^{1}$, Florian Scotte ${ }^{3}$, Benjamin Besse ${ }^{1}$, \\ Jean-Charles Soria"1 and Fabrice Barlesi ${ }^{11,12 \bowtie ~}$
}

Patients with cancer are presumed to be at increased risk of severe COVID-19 outcomes due to underlying malignancy and treatment-induced immunosuppression. Of the first 178 patients managed for COVID-19 at the Gustave Roussy Cancer Centre, 125 (70.2\%) were hospitalized, 47 (26.4\%) developed clinical worsening and 31 (17.4\%) died. An age of over 70 years, smoking status, metastatic disease, cytotoxic chemotherapy and an Eastern Cooperative Oncology Group score of $\geq 2$ at the last visit were the strongest determinants of increased risk of death. In multivariable analysis, the Eastern Cooperative Oncology Group score remained the only predictor of death. In contrast, immunotherapy, hormone therapy and targeted therapy did not increase clinical worsening or death risk. Biomarker studies found that C-reactive protein and lactate dehydrogenase levels were significantly associated with an increased risk of clinical worsening, while C-reactive protein and D-dimer levels were associated with an increased risk of death. COVID-19 management impacted the oncological treatment strategy, inducing a median $20 \mathrm{~d}$ delay in $\mathbf{4 1} \%$ of patients and adaptation of the therapeutic strategy in $30 \%$ of patients.

B y early March 2020, the spread of the coronavirus disease 2019 (COVID-19) outbreak had reached the Paris area, France. Since then, all medical resources have been reorganized to handle the pandemic. As a tertiary cancer center, Gustave Roussy has followed two objectives: define processes to safely sustain cancer care in a secured environment and reorganize internally to adapt its capacities to hospitalize patients with cancer and COVID-19 illness.

Patients with cancer have been considered at increased risk of COVID-19, on the rationale of the increased systemic immunosuppressive state caused by the underlying malignancy and anticancer treatments. The first report from a retrospective cohort in China suggested that patients with cancer were observed to have a higher risk of severe events (for example, a composite endpoint of intensive care unit (ICU) admission, invasive ventilation or death) compared with patients without cancer (seven (39\%) of 18 patients versus $124(8 \%)$ of 1,572 patients; $P=0.0003)$ and that patients with cancer deteriorated more rapidly than those without cancer ${ }^{1}$. While general determinants of COVID-19 severity have emerged from large cohorts from China and Italy ${ }^{2,3}$, limited data are available on the specificity of patients with cancer to help the oncology community to identify patients at risk of severe COVID-19. Furthermore, the impact of COVID-19 infection on ongoing cancer care is unexplored.

This study investigated the determinants of clinical worsening and death, as well as the impact on cancer care, for the first patients sequentially managed for COVID-19 and cancer in an academic tertiary cancer center.

\section{Results}

Patient population. From 24 March 2020 until 29 April 2020, severe acute respiratory syndrome coronavirus 2 (SARS-CoV-2) was detected in 196 (12\%) of 1,633 tests performed internally at the Gustave Roussy Cancer Centre. Overall, 209 patients were identified (including a few identified by PCR with reverse transcription (RT-PCR) performed at another facility and some diagnosed by computed tomography scan alone) and the final study population included 178 adult patients. The following were reasons for exclusion: pediatric population (six patients); non-cancer patients (19 patients); and COVID-19 ultimately ruled out (six patients). Baseline demographics, comorbidities and underlying cancer characteristics for

\footnotetext{
${ }^{1}$ Cancer Medicine Department, Gustave Roussy, Paris-Saclay University, Paris, France. ${ }^{2}$ Biostatistics Department, Gustave Roussy, Paris-Saclay University, Paris, France. Interdisciplinary Cancer Course Department, Gustave Roussy, Paris-Saclay University, Paris, France. ${ }^{4}$ Haematology Department, Gustave Roussy, Paris-Saclay University, Paris, France. ${ }^{5}$ Biopathology Department, Gustave Roussy, Paris-Saclay University, Paris, France. ${ }^{6}$ Pharmacy Department, Gustave Roussy, Paris-Saclay University, Paris, France. ${ }^{7}$ Imaging Department, Gustave Roussy, Paris-Saclay University, Paris, France. ${ }^{8}$ Early Drug Development Department, Gustave Roussy, Paris-Saclay University, Paris, France. ${ }^{9}$ Radiation Oncology Department, Gustave Roussy, Paris-Saclay University, Paris, France. ${ }^{10}$ Paediatric Oncology Department, Gustave Roussy, Paris-Saclay University, Paris, France. "Gustave Roussy, Paris-Saclay University, Paris, France. ${ }^{12}$ Aix Marseille University, CNRS, INSERM, CRCM, Marseille, France. $\varpi_{e}$-mail: Fabrice.BARLESI@gustaveroussy.fr
} 
Table 1 | Patient characteristics

\begin{tabular}{|c|c|c|}
\hline Characteristic & $n$ (out of 178 ) & Percentage \\
\hline \multicolumn{3}{|l|}{ Gender } \\
\hline Male & 76 & $42.7 \%$ \\
\hline Female & 102 & $57.3 \%$ \\
\hline \multicolumn{3}{|l|}{ Age (years) } \\
\hline Median (Q1-Q3) & \multicolumn{2}{|l|}{$61.0(52.0-71.0)$} \\
\hline Mean (s.d.) & \multicolumn{2}{|l|}{$60.6(14.8)$} \\
\hline$\geq 70$ years old & 50 & $28.1 \%$ \\
\hline \multicolumn{3}{|l|}{ Smoking } \\
\hline Never & 89 & $50.6 \%$ \\
\hline Former & 43 & $24.4 \%$ \\
\hline Current & 20 & $11.4 \%$ \\
\hline Unknown & 24 & $13.6 \%$ \\
\hline \multicolumn{3}{|l|}{ Comorbidities } \\
\hline Hypertension & 65 & $36.5 \%$ \\
\hline Diabetes & 35 & $19.7 \%$ \\
\hline Dyslipidemia & 16 & $9.0 \%$ \\
\hline $\begin{array}{l}\text { Cardiac disease } \\
\text { (ischemic/other) }\end{array}$ & $9 / 21$ & $5.1 \% / 11.8 \%$ \\
\hline Chronic kidney disease & 10 & $5.6 \%$ \\
\hline Autoimmune disease & 9 & $5.1 \%$ \\
\hline \multicolumn{3}{|l|}{ BMI } \\
\hline Median (Q1-Q3) & \multicolumn{2}{|c|}{$25.0(22.0-28.0)$} \\
\hline Mean (s.d.) & \multicolumn{2}{|l|}{$25.0(4.9)$} \\
\hline$<18.5$ & 12 & $7.4 \%$ \\
\hline $18.5-25$ & 64 & $39.3 \%$ \\
\hline $25-30$ & 62 & $38.0 \%$ \\
\hline$\geq 30$ & 25 & $15.3 \%$ \\
\hline \multicolumn{3}{|l|}{ History of cancer } \\
\hline Solid tumors & $156^{a}$ & \\
\hline Breast & 32 & $20.5 \%$ \\
\hline Gynecological & 23 & $14.7 \%$ \\
\hline Head and neck & 22 & $14.1 \%$ \\
\hline Gastrointestinal & 21 & $13.5 \%$ \\
\hline Genitourinary & 20 & $12.8 \%$ \\
\hline Thoracic & 17 & $10.9 \%$ \\
\hline Dermatology & 11 & $7.1 \%$ \\
\hline Others (endocrine, CNS, ACUP) & 10 & $6.4 \%$ \\
\hline Hematological malignancies & $30^{a}$ & \\
\hline Mature B cell neoplasm/myeloma & 15 & $50.0 \%$ \\
\hline Acute myeloid leukemia & 8 & $26.7 \%$ \\
\hline Hodgkin lymphoma & 4 & $13.3 \%$ \\
\hline Others & 3 & $10.0 \%$ \\
\hline \multicolumn{3}{|l|}{ Disease status } \\
\hline Remission/curative intent & 70 & $39.3 \%$ \\
\hline Active/advanced disease & 108 & $60.7 \%$ \\
\hline \multicolumn{3}{|l|}{ PS at last oncological visit } \\
\hline $0 / 1$ & 129 & $72.9 \%$ \\
\hline$\geq 2$ & 48 & $27.1 \%$ \\
\hline
\end{tabular}

Table 1 | Patient characteristics (Continued)

\begin{tabular}{|c|c|c|}
\hline Characteristic & $n$ (out of 178) & Percentage \\
\hline \multicolumn{3}{|c|}{ Systemic treatments in the past 3 months } \\
\hline Yes & 117 & $66.9 \%$ \\
\hline Cytotoxic chemotherapy & 66 & $37.1 \%$ \\
\hline Target therapy & 30 & $16.9 \%$ \\
\hline Hormone therapy & 16 & $10.3 \%$ \\
\hline Immune checkpoint inhibitor & 19 & $10.7 \%$ \\
\hline
\end{tabular}

the population are shown in Table 1 . The study population included $102(57.3 \%)$ female patients with a median age of 61 years old and a median body mass index (BMI) of 25 . Among 156 patients with a history of solid tumor, the most frequent were breast cancer $(20.5 \%)$, gynecological cancer $(14.7 \%)$, head and neck tumors (14.1\%), gastrointestinal cancer (13.5\%) and genitourinary malignancies (12.8\%). The most common hematological malignancy was mature $\mathrm{B}$ cell neoplasm, in 15 patients. The disease status at the last oncological or hematological follow-up was remission or localized tumor with ongoing curative treatment in 70 patients (39.3\%) and locally advanced or metastatic disease in 108 patients (60.7\%). The Eastern Cooperative Oncology Group (ECOG) performance status at the last follow-up was $0-1$ in $73 \%$ of patients. Systemic anticancer treatment had been administered in the past 3 months in 117 (66.9\%) patients.

Diagnosis. The vast majority of patients $(n=138 ; 79.8 \%)$ presented with COVID-19 symptoms before any test or imaging. COVID-19 was suspected following symptoms prompting RT-PCR testing in 134 patients $(75.7 \%)$ and following incidental findings on a computed tomography scan in 16 patients $(9 \%)$, and was related to systematic screening (before surgery or another treatment modality) in 27 patients (15.3\%). The most common symptoms reported are presented in Table 2. COVID-19 diagnosis was established by SARS-CoV-2-positive nasal RT-PCR in 166 patients (93.8\%) and by computed tomography scan alone (confirmed by observation of the typical appearance of COVID-19 as defined by the American College of Radiology criteria for patients with a negative RT-PCR test $\left.^{4}\right)$ in 11 patients (6.2\%). Overall, $125(70.2 \%)$ patients were hospitalized for COVID-19 illness. The median time between the first COVID-19 symptoms and admission was $4 \mathrm{~d}(\mathrm{Q} 1-\mathrm{Q} 3=2-8)$. The median duration of hospital stay was $10 \mathrm{~d}$ ( range $=1-40 \mathrm{~d})$.

COVID-19 systemic treatment. Based on the available data, systemic treatment for COVID-19 included a combination of hydroxychloroquine and azithromycin in 45 patients (25.4\%), a combination of lopinavir and ritonavir in five patients $(2.9 \%)$, an immunomodulatory interleukin-6 inhibitor (tocilizumab) in ten patients $(5.6 \%)$ and steroids in 21 patients (11.9\%), mostly administered intravenously with either dexamethasone $(20 \mathrm{mg}$ on days $1-3$ and $10 \mathrm{mg}$ on days 4-6) or $>1 \mathrm{mg} \mathrm{kg}^{-1}$ equivalent prednisone (Supplementary Table 1). Overall, 91 patients (51.4\%) received anticoagulation. Among these 91 patients, anticoagulation was administered with thromboprophylaxis intent (low or intermediate risk: 62\%; high risk: $13 \%)$ or with curative intent (25\%). Among hospitalized patients, 11 patients $(8.8 \%)$ experienced a documented bacterial infection, ten $(8.1 \%)$ presented neurological or psychiatric symptoms and three (2.4\%) developed a thromboembolic event.

Outcome. At data cutoff on 6 May 2020, the median follow-up of the study population from COVID-19 diagnosis was $23 \mathrm{~d}$ (Q1-Q3 = 13-33d). Among the 178 patients, 47 developed clinical 
Table 2 | COVID-19 diagnosis characteristics

\begin{tabular}{|c|c|c|}
\hline Characteristics & $n$ (out of 178) & Percentage \\
\hline \multicolumn{3}{|l|}{ Symptoms before test } \\
\hline Yes & 138 & $79.8 \%$ \\
\hline No & 35 & $20.2 \%$ \\
\hline \multicolumn{3}{|l|}{ Symptoms reported } \\
\hline Fever & 82 & $46.1 \%$ \\
\hline Dry cough & 70 & $39.3 \%$ \\
\hline Fatigue & 52 & $29.2 \%$ \\
\hline Dyspnea & 55 & $30.9 \%$ \\
\hline Diarrhea & 17 & $9.6 \%$ \\
\hline Anosmia & 17 & $9.6 \%$ \\
\hline Ageusia & 14 & $7.9 \%$ \\
\hline \multicolumn{3}{|c|}{ Reported contact with patient with COVID-19 } \\
\hline Yes & 31 & $18.6 \%$ \\
\hline No & 62 & $37.1 \%$ \\
\hline NA & 74 & $44.3 \%$ \\
\hline \multicolumn{3}{|l|}{ COVID-19 diagnosis } \\
\hline RT-PCR SARS-CoV-2 & 166 & $93.8 \%$ \\
\hline CT scan alone & 11 & $6.2 \%$ \\
\hline \multicolumn{3}{|l|}{ Extent of disease at first CT } \\
\hline None/minimal (<10\%) & 68 & $52.7 \%$ \\
\hline Moderate/mild (10-24\%) & 32 & $24.8 \%$ \\
\hline Extensive (25-49\%) & 18 & $14.0 \%$ \\
\hline Severe/critical ( $\geq 50 \%)$ & 11 & $8.5 \%$ \\
\hline NA & 4 & \\
\hline No CT scan performed & 45 & \\
\hline
\end{tabular}

$\mathrm{CT}$, computed tomography; NA, not available.

worsening or died (Table 3), corresponding to a clinical worsening-free survival rate of $73.7 \%$ (95\% confidence interval $(\mathrm{CI})=66.2-79.9 \%) 21 \mathrm{~d}$ after COVID-19 diagnosis. Sixteen patients $(9 \%)$ had been admitted to the ICU. The median time from the first COVID-19 symptoms to clinical worsening was $7 \mathrm{~d}$ ( minimum $=1 \mathrm{~d}$; maximum $=19 \mathrm{~d})$. Overall, 31 patients died, corresponding to an overall survival rate of $82 \%$ (95\% CI $=74.9-87.4 \%)$ $21 \mathrm{~d}$ after COVID-19 diagnosis. Among them, the primary cause of death was related to COVID-19 in 20 patients (64.5\%) and to cancer in 11 patients $(35.5 \%)$.

Cancer-related determinants of clinical worsening-free and overall survival in patients with cancer and COVID-19. Univariable and multivariable analyses of both clinical worsening-free and overall survival are presented in Table 4 . In univariable analysis, an ECOG score of $\geq 2$ at the last follow-up visit, smoking status (current and former) and the use of cytotoxic chemotherapy in the past 3 months were significantly associated with clinical worsening-free survival. A similar trend was observed according to the type of cancer (hematological malignancy). Determinants of increased risk of death, in univariable analysis, were age $\geq 70$ years, smoking status (current and former), an ECOG score of $\geq 2$ at the last follow-up, onco-hematological status (metastatic disease) and the use of cytotoxic chemotherapy in the past 3 months (Figs. 1 and 2). Among patients treated with cytotoxic chemotherapy in the past 3 months and presenting clinical worsening $(n=26)$, four out of five $(80 \%)$ patients in remission or with localized disease were admitted to the ICU versus five out of 21 patients (24\%) with locally advanced or
Table 3 | Clinical outcome and impact on oncological treatment

\begin{tabular}{lll} 
Outcome & $\boldsymbol{n}$ (out of 178) & Percentage \\
\hline Hospital admission & 125 & $70.2 \%$ \\
Clinical worsening & 47 & $26.4 \%$ \\
Admission to ICU & 16 & $9.0 \%$ \\
At data cutoff & & \\
Death & 31 & $17.4 \%$ \\
$\quad$ Primary cause of death: COVID-19 & 20 & \\
$\quad$ Primary cause of death: cancer & 11 & \\
Never hospitalized & 51 & $28.7 \%$ \\
Still hospitalized & 16 & $9.0 \%$ \\
Discharged & 80 & $44.9 \%$ \\
Impact of CoVID-19 on cancer treatment & \\
No change in strategy & & \\
$\quad$ No delay in ongoing treatment & 51 & $41.2 \%$ \\
$\quad$ Delay in ongoing treatment & 73 & \\
Change in strategy & & $1.1 \%$ \\
$\quad$ Dose modification & 2 & $3.4 \%$ \\
Change of treatment modality & 6 & $4.0 \%$ \\
Change of systemic therapy & 7 & $4.0 \%$ \\
End of treatment (surveillance) & 7 & \\
End of treatment (palliative care or & 31 & \\
death) & & \\
NA & 1 & \\
\hline
\end{tabular}

Data cutoff was 6 May 2020. The median follow-up was 23d.

metastatic disease $(P=0.035)$. Conversely, hormone therapy, targeted therapies and immune checkpoint inhibitors had no impact on the COVID-19 outcomes. Only 11 patients (6\%) were receiving radiation therapy at the time of COVID diagnosis. Three patients presented with clinical deterioration (two with a gynecological cancer and one with a renal cell carcinoma metastatic to the bone). Among them, one patient eventually died from COVID-19. In multivariable analysis, an ECOG score of $\geq 2$ at the last follow-up was the strongest determinant associated with both clinical worsening and death.

Baseline biological determinants of clinical worsening-free and overall survival in patients with cancer and COVID-19. Several biological factors, markers of infection, inflammatory status and underlying conditions have been investigated for their association with either the risk of clinical worsening or the risk of death and are presented in Table 5. Among these, C-reactive protein (CRP) $>50 \mathrm{mg} \mathrm{ml}^{-1}$, procalcitonin $>0.5 \mu \mathrm{gl}^{-1}$, lymphopenia $\leq 500$ cells per $\mu \mathrm{l}$, monocytopenia $\leq 200$ cells per $\mu \mathrm{l}$, ferritin $>1,000 \mathrm{ng} \mathrm{ml}^{-1}$, lactate dehydrogenase $(\mathrm{LDH})>250 \mathrm{IUl}^{-1}$, albumin $\leq 30 \mathrm{gl}^{-1}$ and troponin $>$ upper limit of normal (ULN) were associated with a significantly increased risk of both clinical worsening and death in univariable analysis. In multivariable analysis, CRP and LDH were significantly associated with an increased risk of clinical worsening, and CRP and D-dimer $>3 \mu \mathrm{gl}^{-1}$ were associated with an increased risk of death.

Impact of COVID-19 on oncological strategy. The results of a post-COVID-19 first-month assessment were available for 146 patients: $75 \%$ reported persistent symptoms of asthenia, $42 \%$ reported exertion dyspnea and 30\% reported a cough. Among 141 patients with available information, 87 (62\%) had cancer-specific treatment already restarted or planned. The overall impact of 


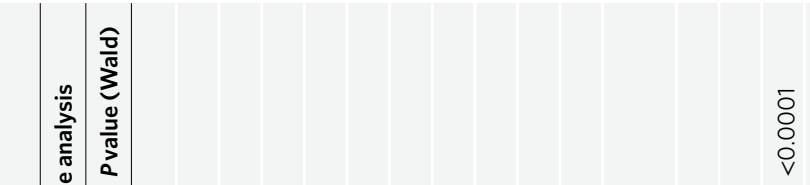<smiles>C1CCCCC1</smiles>

$\stackrel{\frac{10}{\circ}}{\circ}$ $\stackrel{m}{0}$

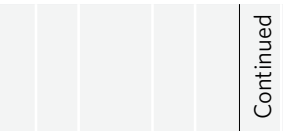

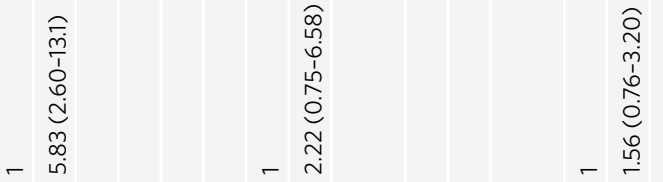

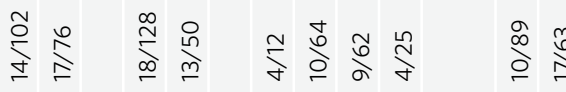

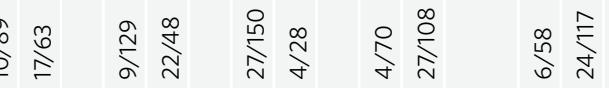

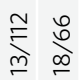

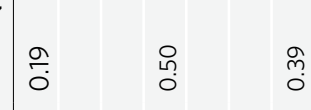

vi

oे
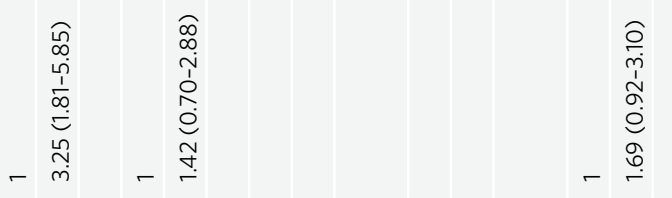

$\stackrel{\infty}{\sim}$ 유

ㄷำ

$\infty$
$\infty$
$\infty$
$\stackrel{N}{N}$
$\stackrel{N}{N}$

$\stackrel{\text { సิ }}{\stackrel{\infty}{\longleftarrow}}$

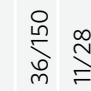

$\stackrel{\infty}{\stackrel{\infty}{\infty}} \stackrel{\infty}{\frac{\infty}{2}}$

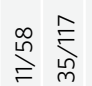

స

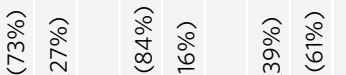

òे

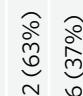
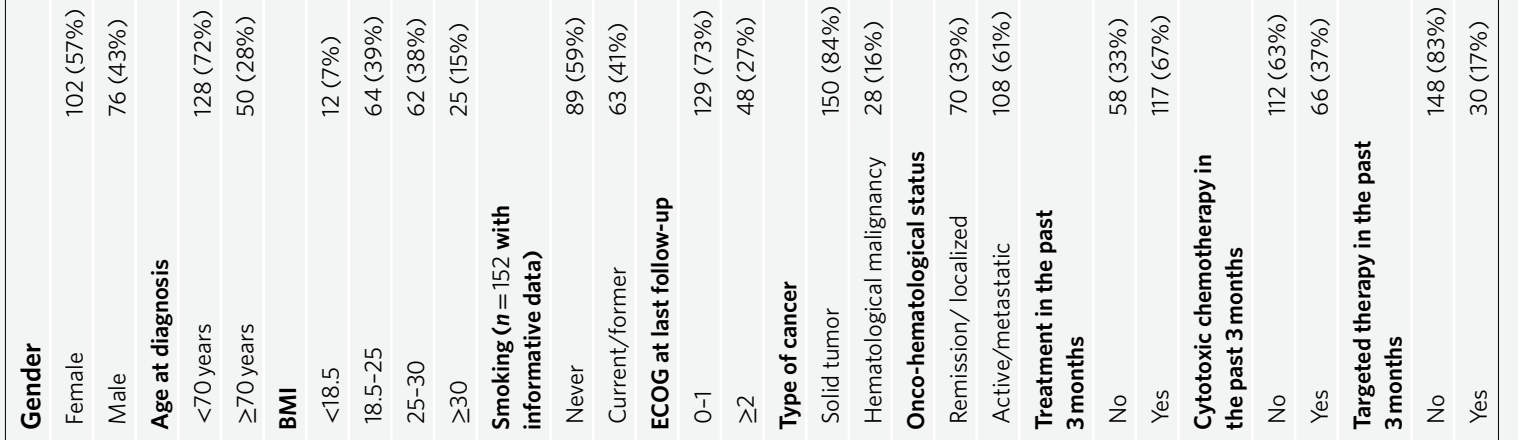


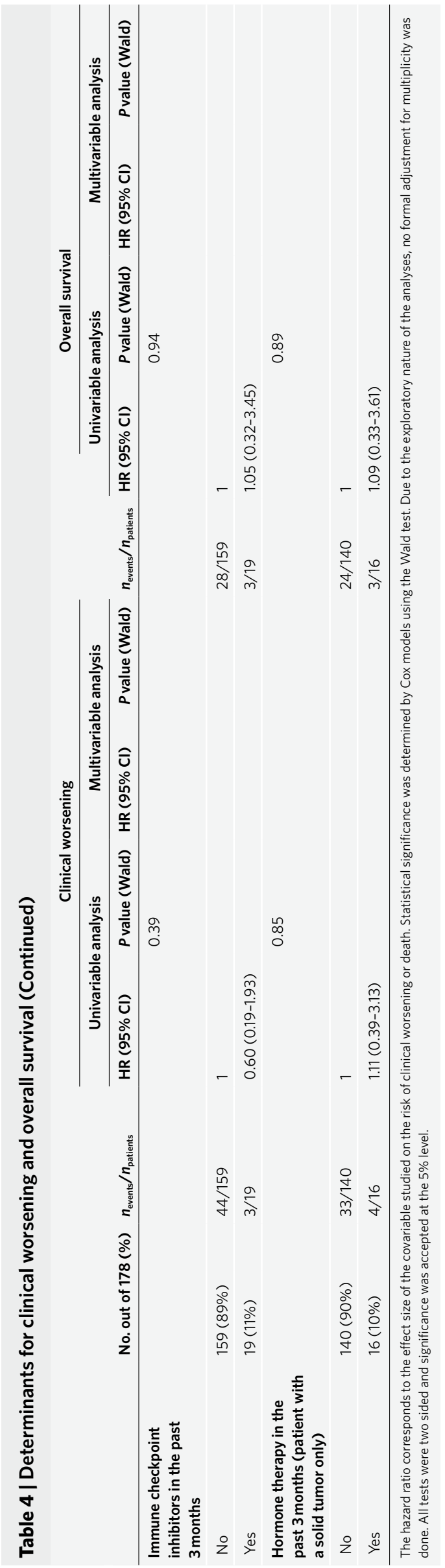

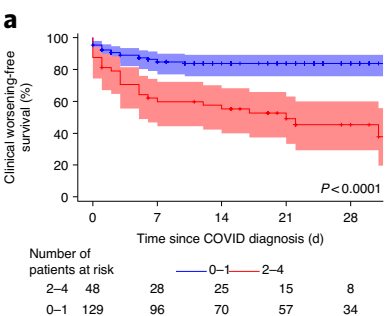

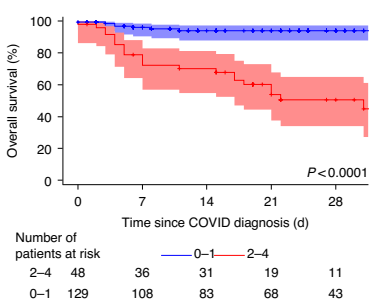

b
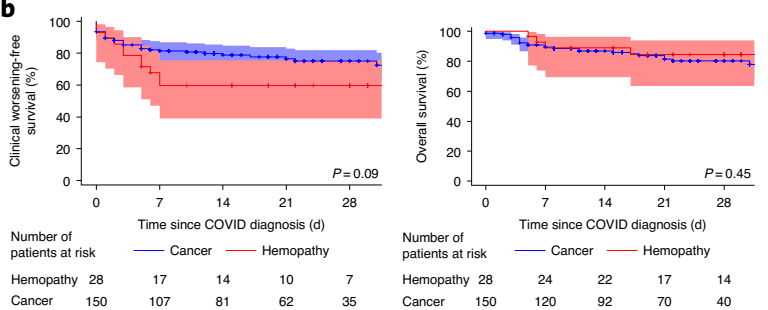

c
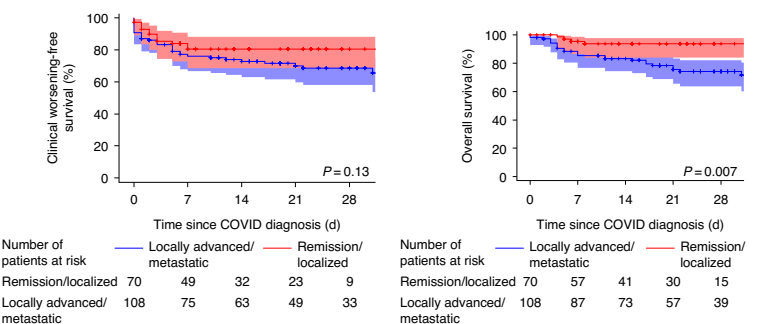

d
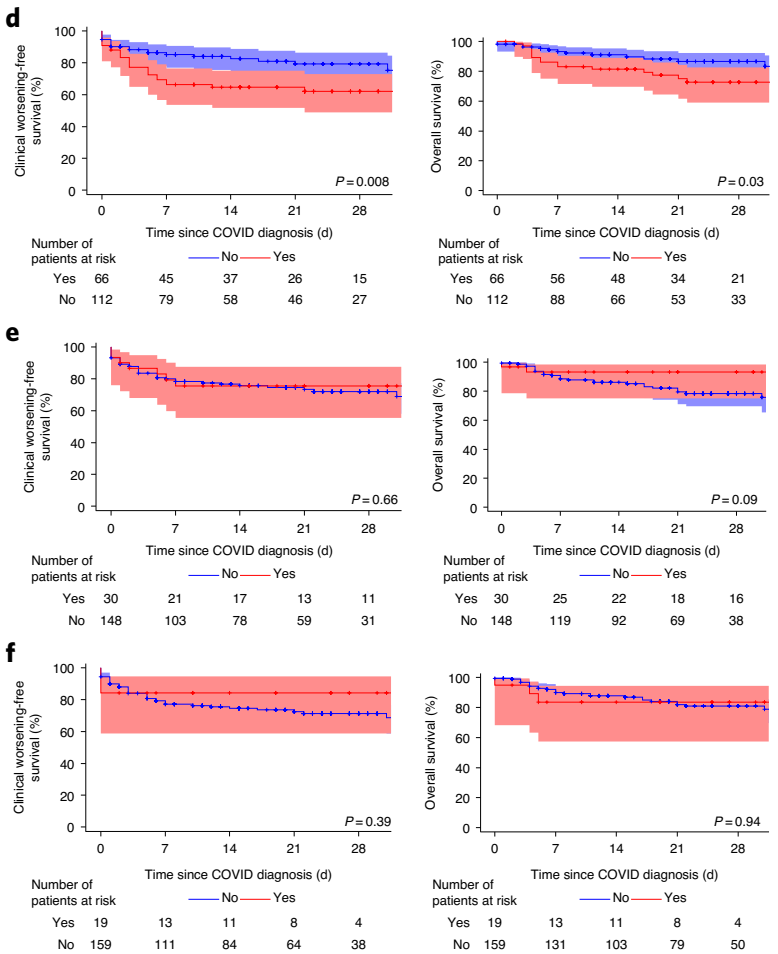

Fig. 1 | Determinants for clinical worsening and overall survival. a-f,

Kaplan-Meier plots ( $n=178$ patients) of clinical worsening-free survival (left) and overall survival (right), stratified according to ECOG score at the last onco-hematological consultation $(n=177)$ (a), type of cancer $(n=178)(\mathbf{b})$, onco-hematological status $(n=178)(\mathbf{c})$, administration of cytotoxic chemotherapy inhibitors in the past 3 months $(n=178)$ (d), administration of targeted therapy inhibitors in the past 3 months $(n=178)(\mathbf{e})$ and administration of immune checkpoint inhibitors in the past 3 months $(n=178)(\mathbf{f})$. Pointwise $95 \%$ confidence limits are reported (shaded intervals). Plus symbols indicate censored observations. Statistical significance was determined by Wald test of the univariable Cox models. 

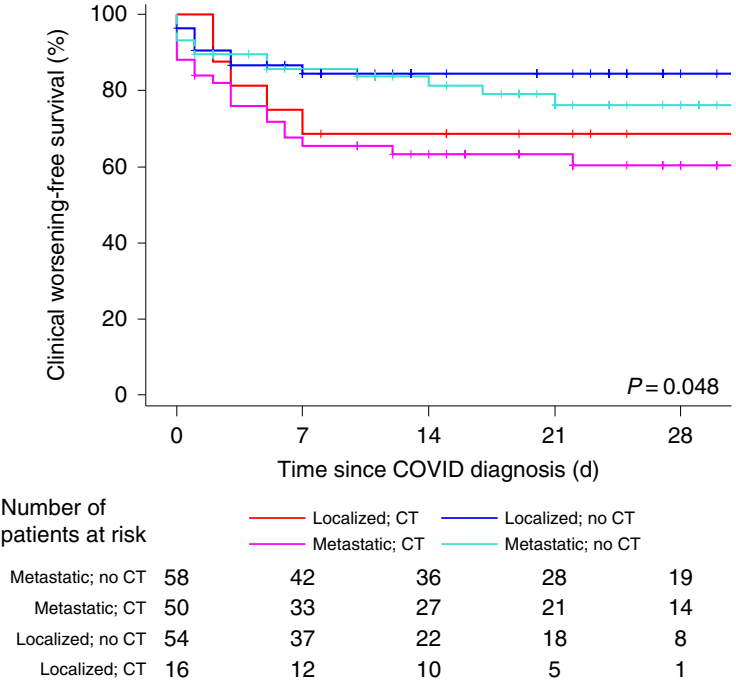

\begin{tabular}{cccc} 
L Localized; $C T$ & \multicolumn{2}{c}{ Localized; no CT } \\
Metastatic; & CT & Metastatic; no CT \\
42 & 36 & 28 & 19 \\
33 & 27 & 21 & 14 \\
37 & 22 & 18 & \\
12 & 10 & 5
\end{tabular}

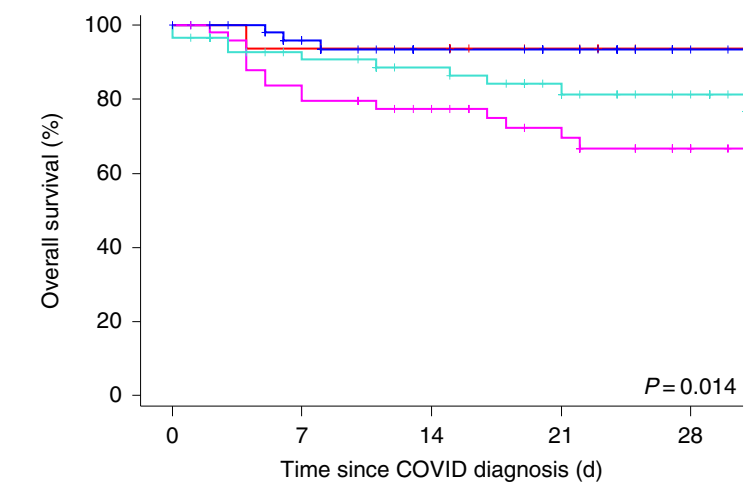

Number of patients at risk Metastatic; no CT 58 Metastatic; CT 50 Localized; no CT 54 Localized; CT 16

Fig. 2 | Impact of cytotoxic chemotherapy according to cancer status. Kaplan-Meier plots of clinical worsening-free survival (left) and overall survival (right), stratified according to cytotoxic chemotherapy in the past 3 months and onco-hematological status. Plus signs indicate censored observations. For all comparisons, $n=178$ patients. Statistical significance was determined by Wald test of the univariable Cox models. CT, chemotherapy.

COVID-19 on cancer treatment was assessed in the entire cohort (Table 3), leading to no change in oncological care management in 51 patients (29\%). These included 28 patients who were under surveillance before COVID-19 and remained under surveillance, as well as 22 patients with ongoing oncological or hematological treatment for whom COVID-19 did not impact the ongoing care. In 73 patients (41\%), COVID-19 diagnosis induced a delay but no change in the strategy, with a median delay of $20 \mathrm{~d}$ (interquartile range (IQR): 12-30 d) for systemic therapy and $28 \mathrm{~d}$ (IQR: 22-44d) for surgery or ablative techniques. A change in oncological care management (such as surgery anticipation or switch to radiotherapy) was reported in $4 \%$ of patients, and a change in systemic therapy was reported in $4 \%$ of patients. The COVID-19 illness led to a discontinuation of cancer treatment in $4 \%$ of patients for the surveillance-only strategy. Among patients with any impact (delay, change or end of treatment), $78 \%$ of these changes were related to COVID-19, 18\% were related to underlying cancer progression and $4 \%$ were related to cancer treatment toxicity. Among 11 patients who were diagnosed with COVID-19 while undergoing ongoing radiation therapy, four had an interruption in the radiation plan, and among eight patients with planned radiation therapy at the time of COVID-19 diagnosis, three had the start of radiation treatment delayed by $>7 \mathrm{~d}$.

\section{Discussion}

The outcomes of COVID-19 illness have been analyzed in previous datasets ${ }^{2,3,5,6}$ but data on predictors of disease severity specifically in patients with cancer are limited and the impact on cancer treatment is unknown. In this study, we report on COVID-19 management at a tertiary cancer center and investigate determinants of clinical worsening and death, as well as the impact on cancer care.

This study identified that $12 \%$ of the tested population were positive for COVID-19. COVID-19 led to a death rate of $17.4 \%$, similar to the concomitant mortality of admitted patients with COVID-19 in the Paris area (https://www.gouvernement.fr/info-coronavirus/ carte-et-donnees). Conflicting results have been reported recently on a potential increased risk of severe COVID-19 outcome in patients with cancer. A cohort of 5,688 patients, including 334 patients with cancer, did not identify any increased risk of death in patients with cancer $(\mathrm{HR}=1.15(95 \% \mathrm{CI}=0.84-1.57))^{7}$, while an analysis of 105 patients with cancer and 536 age-matched patients without cancer suggested that patients with cancer have higher risks for all severe outcomes related to COVID-19 and an excess odds ratio of $2.17(P=0.06)$ for death ${ }^{8}$. More recently, the OpenSAFELY study suggested there is increased COVID-19 mortality in patients with a recent diagnosis of solid tumors ${ }^{6}$.

Recently, two large retrospective international cohorts have been reported on, including all patients with cancer in the COVID19 and Cancer Consortium (CCC19) study ${ }^{9}$ and all patients with thoracic cancer in the Thoracic Cancers International COVID-19 Collaboration (TERAVOLT) study ${ }^{10}$. Using a similar design, these two studies investigated factors associated with COVID-19 mortality. The design and results of these two studies, along with the current study and two others, are presented in Table 6, which summarizes the specificity of each cohort.

In our cohort, we observed a trend towards severe COVID-19 in patients with hematological malignancies (crude hazard ratio $(\mathrm{HR})=1.80(95 \% \mathrm{CI}=0.91-3.55) ; P=0.09)$, as reported in other datasets $^{6,11}$. However, in our experience, this factor was not associated with a significant increased risk of death, potentially related to both a more intensive care strategy and the limited number of hematological patients in our cohort. The granularity of our dataset has enabled the investigation of several determinants including the impact of cancer status (remission or localized versus metastatic or advanced), the impact of the systemic anticancer treatment used and the ECOG performance status at the last oncological follow-up before COVID-19 diagnosis. Our analysis suggests that cancer status may not impact the risk of clinical worsening but seems to be associated with an increased risk of death (univariable analysis). With regard to systemic anticancer therapy, we did not identify a detrimental effect of the use of immune checkpoint inhibitors, hormone therapy or targeted therapy on the risk of clinical worsening or death. While some initial reports suggested a potential increased severity of COVID-19 with immune checkpoint inhibitors ${ }^{8}$, a more recent dataset including two cohorts of patients with lung cancer similarly concluded that programmed cell death protein 1 blockade exposure is not associated with an increased risk of severity of COVID-19 (refs. ${ }^{10,12}$ ). Conversely, the use of cytotoxic chemotherapy was associated with an increased risk of clinical worsening and death in univariable analysis and showed a trend for a higher risk of death after adjustment of ECOG performance status and cancer status in multivariable analysis. This may be partially explained by more intensive care solicitation in patients receiving 

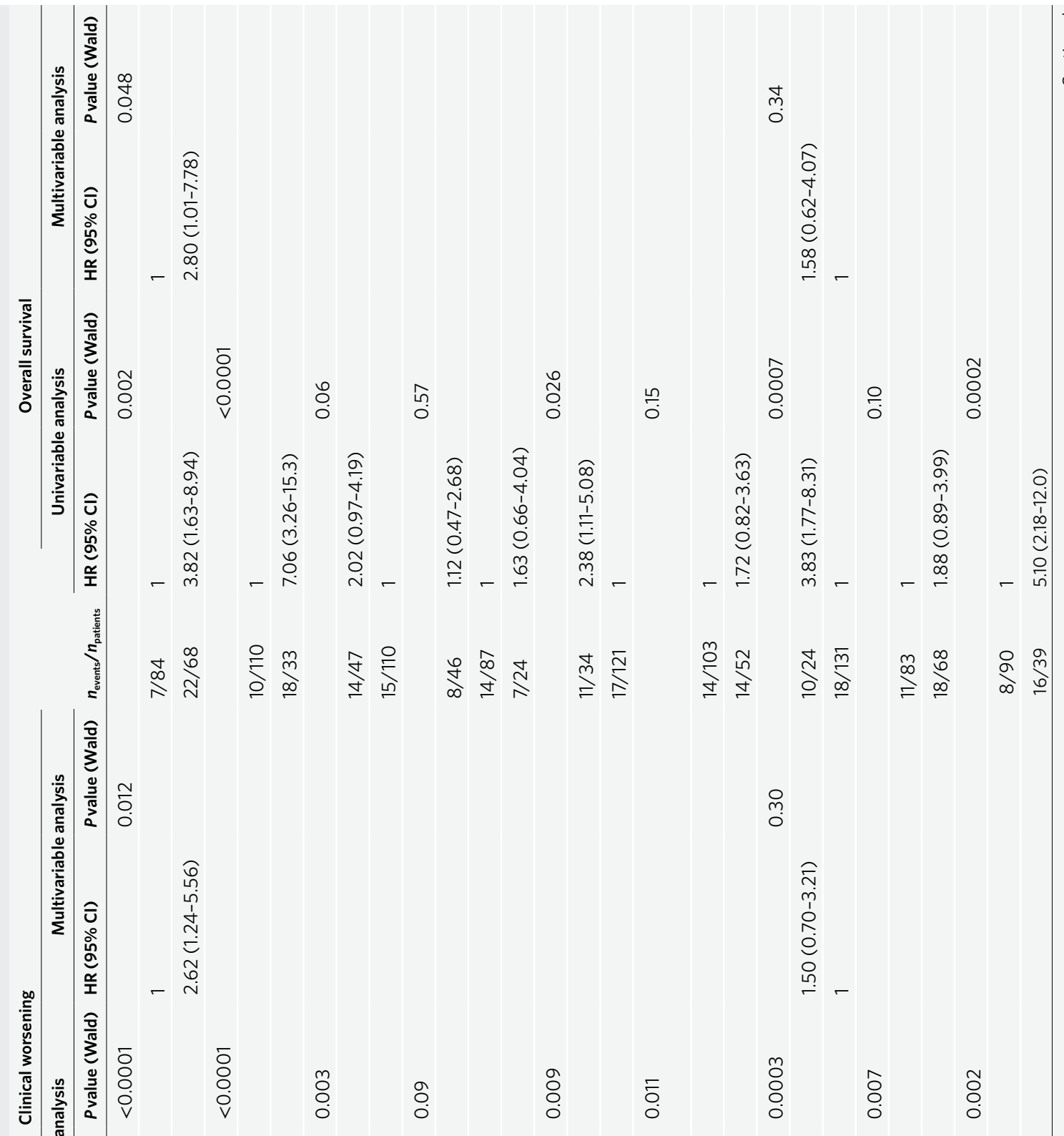

$\begin{array}{ll}\overline{0} & \\ \vdots & 0 \\ 0 & 0 \\ 0 & 0\end{array}$

$\begin{array}{ll}m & 0 \\ 0 & 0 \\ 0 & 0\end{array}$

oे

ธั.

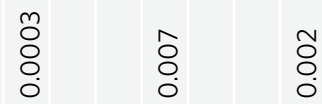

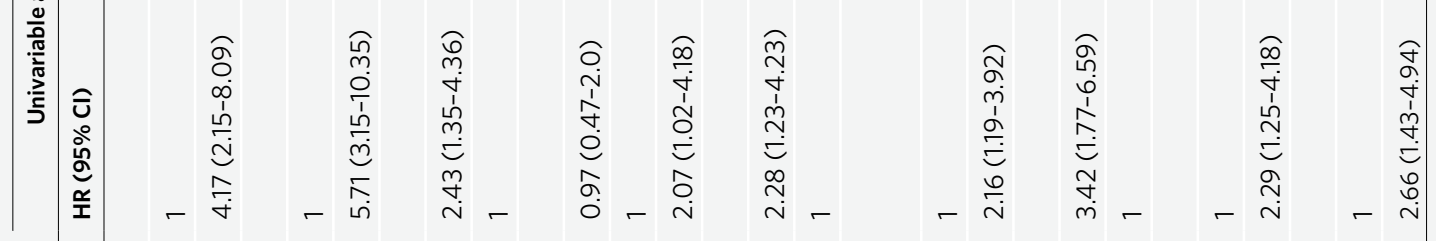

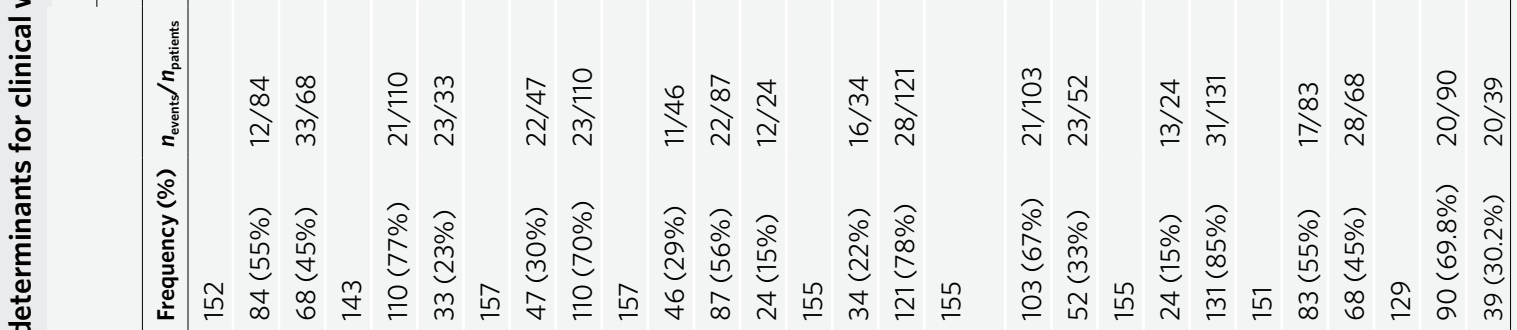

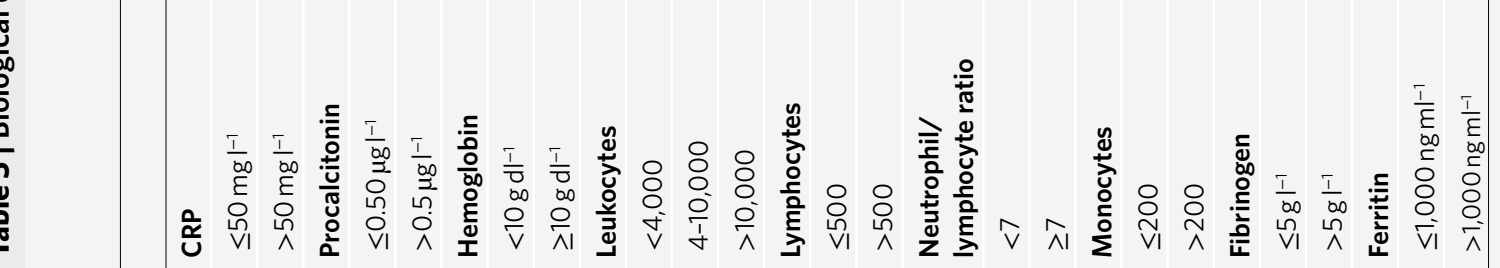




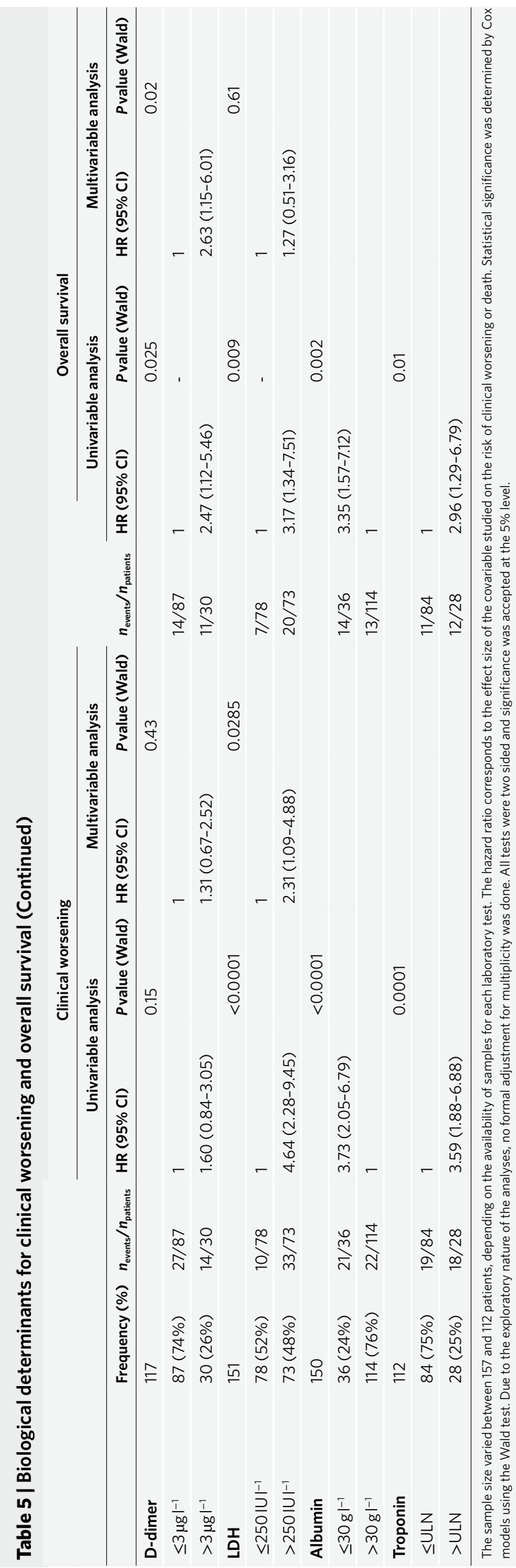

cytotoxic chemotherapy in the setting of remission or localized disease. Similarly, the UK Coronavirus Cancer Monitoring Project did not identify evidence that patients with cancer who are on cytotoxic chemotherapy or another anticancer treatment are at an increased risk of mortality from COVID-19 disease compared with those not on active treatment ${ }^{13}$. In our experience, an ECOG score of $\geq 2$ at the last oncological follow-up remains in multivariable analysis the strongest determinant of both increased risk of clinical worsening and increased risk of death.

Patient characteristics and prognostic models in our population highlight the fact that patients with cancer may not harbor the specific patterns of comorbidities reported in large COVID-19 series $^{2,3,5}$. Our dataset identified a trend towards worse outcomes in patient with a BMI $>30$, but the lack of a significant impact of BMI may be driven by underlying oncological disease and nutritional status in advanced oncological states, as captured in patients with a $\mathrm{BMI}<18.5$ or albumin $<30 \mathrm{gl}^{-1}$ in our cohort.

Several datasets have reported on the association of current smoking with favorable outcomes of COVID-19 (refs. ${ }^{2,14}$ ). Conversely, we report a detrimental effect of current or former smoking status on outcomes that may be driven by the underlying smoking-related malignancies in our population.

Furthermore, we investigated the role of several biological markers in disease outcome in patients with cancer. While levels of CRP and other inflammatory factors have been reported previously, we identified lymphopenia and monocytopenia as relevant markers associated with clinical worsening. Emerging data on a cohort of 142 patients in which blood markers (CRP, procalcitonin, interleukin-6, lymphocyte count and viral load (ORF1ab Ct)) were explored as predictors of survival in patients with COVID-19 have recently shown that lymphopenia is the strongest predictor for severity disease in patients with COVID-19 (ref. ${ }^{15}$ ). Of note, lymphopenia has long been established as a prognostic factor for overall survival in patients with cancer ${ }^{16}$. We report on the potential role of monocytopenia as a predictor of clinical worsening. This finding is in line with recent immune cell profiling of patients with COVID-19 identifying that monocyte levels increased in patients in the early recovery stage of COVID-19 (ref. ${ }^{17}$ ). Additionally, recent evidence suggests that pathological macrophages mostly derive from circulating monocytes that massively infiltrate the lungs ${ }^{18}$. Monocytes are considered to have the potential to differentiate into pro-inflammatory macrophages via activation of Janus kinase-signal transducer and activator of transcription (JAK-STAT) pathways and to contribute to hyper-inflammation associated with COVID-19 (ref. ${ }^{19}$ ).

Our dataset explores the impact of COVID-19 on cancer management. Beyond the emerging data raising the concern of fewer cancer diagnoses during the COVID-19 pandemic ${ }^{20}$, the impact on ongoing cancer care, including delays of treatment and halting of clinical trials, has been identified ${ }^{2}$. Our dataset identified a high incidence of delays, but the median time to anticancer systemic therapy or rescheduled surgery was $<1$ month. To ensure that patients continue to receive essential care while minimizing exposure to SARS-CoV-2 infection, cancer centers have organized their healthcare systems at an unprecedented scale and $\mathrm{pace}^{22}$. As such, we have amended our CAPRI telemedicine program, which was initially set up to monitor patients with cancer undergoing oral therapy, to face the ongoing COVID-19 crisis. The remote telemedicine monitoring strategy has been adapted to monitor outpatients positive for COVID-19 after they have provided informed consent ${ }^{23}$.

Our study did not address the management of our pediatric patient population. At the institution level, it was decided that all pediatric patients should be tested routinely, and among 122 patients $<18$ years of age tested internally, $5 \%$ were found to be positive (minimum $=22$ months; maximum $=13$ years). Dedicated analysis is planned for the management of this specific population. 
Table 6 | Study design and results for five studies investigating COVID-19 mortality in patients with cancer infected with SARS-Cov-2

\begin{tabular}{|c|c|c|c|c|c|}
\hline Data & CCC19 (ref. $\left.{ }^{9}\right)$ & $\begin{array}{l}\text { UK Coronavirus } \\
\text { Cancer Monitoring } \\
\text { Project }^{13}\end{array}$ & Gustave Roussy cohort & TERAVOLT ${ }^{10}$ & Curie cohort ${ }^{34}$ \\
\hline $\begin{array}{l}\text { Patients with } \\
\text { cancer }(n)\end{array}$ & 928 & 800 & 178 & 200 & 76 \\
\hline Cancer population & All cancers & All cancers & All cancers & Thoracic cancer & Breast cancer \\
\hline Multicentric & Yes & Yes & No & Yes & No \\
\hline $\begin{array}{l}\text { Inclusion of } \\
\text { biological findings }\end{array}$ & No & No & Yes & No & Yes \\
\hline $\begin{array}{l}\text { Inclusion of CT } \\
\text { findings }\end{array}$ & No & No & Yes & No & Yes \\
\hline $\begin{array}{l}\text { Inclusion of } \\
\text { COVID-19 systemic } \\
\text { treatment used }\end{array}$ & Yes & No & Yes & No & Yes \\
\hline $\begin{array}{l}\text { Inclusion of impact } \\
\text { on cancer treatment } \\
\text { strategy after } \\
\text { COVID-19 diagnosis }\end{array}$ & No & No & Yes & No & No \\
\hline $\begin{array}{l}\text { Prognostic factors } \\
\text { of death studied in } \\
\text { univariable analysis }\end{array}$ & $\begin{array}{l}\text { Increased age (per } 10 \text { years), } \\
\text { male sex, smoking status } \\
\text { (former smoker versus } \\
\text { never smoked), number of } \\
\text { comorbidities (two versus } \\
\text { none), type of malignancy } \\
\text { (multiple cancers versus } \\
\text { only solid tumor), active } \\
\text { cancer (progressing } \\
\text { versus remission), ECOG } \\
\text { score } \geq 2 \text { and azithromycin/ } \\
\text { hydroxychloroquine treatment }\end{array}$ & $\begin{array}{l}\text { Age, male sex, } \\
\text { hypertension, } \\
\text { cardiovascular } \\
\text { disease, COVID- } \\
19 \text { severity score, } \\
\text { ICU admission and } \\
\text { shortness of breath }\end{array}$ & $\begin{array}{l}\text { Age } \geq 70 \text { years, smoking } \\
\text { status (current and } \\
\text { former), ECOG score } \geq 2 \\
\text { at last follow-up, } \\
\text { onco-hematological } \\
\text { status (metastatic } \\
\text { disease), use of cytotoxic } \\
\text { chemotherapy in past } \\
3 \text { months and levels of CRP, } \\
\text { procalcitonin, lymphopenia, } \\
\text { monocytopenia, ferritin, } \\
\text { LDH, albumin and troponin }\end{array}$ & $\begin{array}{l}\text { Age }>65 \text { years, } \\
\text { smoking status } \\
\text { (current versus former } \\
\text { smoker), treatment } \\
\text { with chemotherapy, } \\
\text { presence of any } \\
\text { comorbidities and } \\
\text { dyspnea }\end{array}$ & $\begin{array}{l}\text { Age } \\
(>70 \text { years }) \\
\text { and } \\
\text { hypertension }{ }^{\text {a }}\end{array}$ \\
\hline $\begin{array}{l}\text { Prognostic factors } \\
\text { of death studied in } \\
\text { multivariate analysis }\end{array}$ & $\begin{array}{l}\text { Increased age }(\mathrm{OR}=1.84 ; \\
95 \% \mathrm{Cl}=1.53-2.21), \text { male sex } \\
(\mathrm{OR}=1.63 ; 95 \% \mathrm{Cl}=1.07-2.48) \text {, } \\
\text { smoking status }(\mathrm{OR}=1.60 ; \\
95 \% \mathrm{Cl}=1.03-2.47), \text { number } \\
\text { of comorbidities }(2 \text { versus } 0) \\
(\mathrm{OR}=4.50 ; 95 \%=1.33-15.28) \\
\mathrm{ECOG} \text { score } \geq 2(\mathrm{OR}=3.89 ; 95 \% \\
\mathrm{Cl}=2.11-7.18), \text { active cancer } \\
\text { (progressing versus remission) } \\
(\mathrm{OR}=5.20 ; 95 \% \mathrm{Cl}=2.77- \\
9.77) \text { and azithromycin/ } \\
\text { hydroxychloroquine treatment } \\
(\mathrm{OR}=2.93 ; 95 \% \mathrm{Cl}=1.79-4.79)\end{array}$ & None $^{b}$ & $\begin{array}{l}\text { ECOG score at last } \\
\text { follow-up } \geq 2(\mathrm{HR}=5.83 ; \\
95 \% \mathrm{Cl}=2.60-13.1), \mathrm{CRP} \\
\text { levels }(\mathrm{HR}=2.80 ; 95 \% \\
\mathrm{Cl}=1.01-7.78) \text { and } \mathrm{D} \text {-dimer } \\
\text { levels }(\mathrm{HR}=2.63 ; 95 \% \\
\mathrm{Cl}=1.15-6.01)\end{array}$ & $\begin{array}{l}\text { Smoking history } \\
(\mathrm{OR}=3.18 ; 95 \% \\
\mathrm{Cl}=1.11-9.06)\end{array}$ & Not done \\
\hline
\end{tabular}

${ }^{a}$ Death or ICU admission. ${ }^{b}$ Multivariable analysis was only done for cancer treatment. There was no significant effect on mortality for patients who received chemotherapy in the past 4 weeks, immunotherapy, hormonal therapy, targeted therapy, or radiotherapy in the past 4 weeks. CT, computed tomography; OR, odds ratio.

The retrospective nature of this work from a single institution and the heterogeneity of our cancer center population are inherent limitations to our study. Due to the small sample size and relatively low number of events, multivariable models were only adjusted on the main prognostic factors. Some analyses may have failed to identify other determinants of clinical deterioration and overall survival by lack of power. As a result of the testing strategy (mainly in symptomatic patients who were likely to have more severe infection), our results may not apply to asymptomatic and paucisymptomatic patients with cancer. However, this highlights the challenges that 
cancer centers have faced when handling the COVID-19 pandemic: the need for daily fine-tuned patient management and the need to inform the community on strategies to ensure our patients with cancer have access to essential care in an adjusted environment.

In summary, cancer centers had to face the COVID-19 outbreak with the concomitant objective to secure patients' care while protecting them from the infection. Globally, these objectives have been reached, with COVID-19 outcomes comparable to those of the general population and cancer care minimally delayed and already safely restarted.

\section{Methods}

Statistics and reproducibility. Study design. We performed a retrospective observational study to describe the management of adult patients with cancer (solid tumors or hematological malignancies) managed at the Gustave Roussy Cancer Centre after a diagnosis of SARS-CoV-2 infection (COVID-19) between 14 March 2020 and 29 April 2020. The modalities of COVID-19 diagnosis, clinical presentation, treatments administered for COVID-19 and patient outcomes, including impacts on cancer management, are reported. The aim of the study was to identify clinical and biological prognostic factors of clinical worsening and/ or death. No statistical method was used to predetermine sample size. A total of 31 observations were excluded from the final analysis: six pediatric patients; 19 patients who did not have cancer; and six patients in whom COVID-19 was ultimately ruled out. Due to the retrospective nature of this study, there was neither randomization nor blinding.

Measures. Prognostic factors included demography (age and gender), comorbidities, solid tumor or hematological malignancies (tumor site and type, disease status and treatment received) and biological factors from laboratory tests at COVID19 diagnosis. All of the measurements were performed independently in each patient (no repeated measurements were done). Biological factors were categorized using pre-defined threshold values based on normal value cutoffs or recently published cutoffs for the study of COVID-19. Chest computed tomography imaging characteristics, including the extent of lung involvement at diagnosis, were recorded.

Outcomes. The outcomes studied were clinical worsening-free survival and overall survival. Clinical worsening-free survival was defined as the time from COVID-19 diagnosis to clinical worsening (oxygen needs $\geq 61 \mathrm{~min}^{-1}$ or admission to the ICU) or death. Overall survival was defined as the time from COVID-19 diagnosis to death from any cause. These outcomes were chosen because they are objective, reliably recorded and reflect the increasing severity of COVID-19, as recommended by the World Health Organization for the assessment of patients in clinical studies ${ }^{24}$

Statistical analysis. Descriptive statistics (numbers, percentages, medians, IQRs and ranges) were used to describe population characteristics. The $\chi^{2}$ test (or Fisher's test) and Student's $t$-test (or Wilcoxon test) were performed for intergroup comparisons, as appropriate. Time-to-event endpoints (clinical worsening-free survival and overall survival) were reported using the Kaplan-Meier method with Rothman's CIs. For the study of clinical and biological prognostic factors, Cox's proportional hazard models were used to provide $P$ values and HRs with associated $95 \%$ CIs in both univariable and multivariable analyses. The choice of variables to include in the multivariable analyses was driven by the number of events available (three to four variables were included for 47 clinical worsenings/deaths and 31 deaths), the strength of the association in the univariable analyses and the absence of collinearity between variables included in the model (assessed by $\chi^{2}$ test and Fisher's test for qualitative variables or Spearman's correlation coefficient for quantitative variables). The assumption of proportional hazards was checked by testing the existence of an interaction between each variable and log[time] in each model. Due to the exploratory nature of the analyses, no formal adjustment for multiplicity was done. All tests were two sided and significance was accepted at the $5 \%$ level. The analyses were performed using SAS 9.4 software (SAS institute).

Database and ethical approval. Study data were collected and managed using REDCap 9.8.4 tools hosted at the Gustave Roussy Cancer Centre ${ }^{25,26}$. In accordance with the French regulations, there was no requirement for ethical approval to be sought for this observational study, based on medical files. Conforming to the General Data Protection Regulation and French law about clinical retrospective studies, the patients included in our study all received an information notice (non-opposal information) introducing the study, following information included in Article 14 of the General Data Protection Regulation, and describing their rights in relation to their data. This study was also declared to the Gustave Roussy Cancer Centre's data protection officer and registered on the website of the French Healthcare Data Institute (declaration number: MR4911200520).

COVID-19 screening strategy. Due to testing resources, the screening strategy for SARS-CoV-2 infection evolved over the course of the reported study. Initially,
PCR testing was performed for symptomatic patients. Subsequently, there was systematic screening of non-symptomatic patients scheduled for surgery and/or radiation therapy, as well as in the pediatric population. Ultimately, testing was offered to any patients with a solid tumor or hematological malignancies as part of the ongoing ONCOVID clinical trial (Epidemiology of SARS-CoV-2 and Mortality to COVID-19 Disease in French Cancer Patients; NCT04341207).

COVID-19 PCR testing. SARS-CoV-2 diagnostic testing of clinical samples by RT-PCR was conducted from 14 March to 23 March at an outside facility (263 patients were tested, of whom 35 were found to be positive) using the Charité protocol $^{27}$. From 23 March, testing was performed internally at the Gustave Roussy Cancer Centre.

Nasopharyngeal swab samples were collected using flocked swabs (Sigma Virocult) and placed in viral transport media. SARS-CoV-2 RNA was detected using a multiplex real-time RT-PCR diagnostic kit (the Applied Biosystems TaqPath COVID-19 CE-IVD RT-PCR Kit) targeting three regions (ORF1ab, nucleocapsid and spike genes) with the following modifications. Nucleic acids were extracted from specimens using automated Maxwell instruments following the manufacturer's instructions (Maxwell RSC simplyRNA Blood Kit; AS1380; Promega). Real-time RT-PCR was performed on the QuantiStudio 5 Dx Real-Time PCR System (Thermo Fisher Scientific) in a final reaction volume of $20 \mu \mathrm{l}$, including $5 \mu \mathrm{l}$ of extracted nucleic acids. Samples were reported as positive if at least two targets were detected.

COVID-19 and oncological treatment strategies. COVID-19 therapeutic management has been defined through institutional guidelines (Extended Data Fig. 1). These institutional guidelines were adjusted over time, depending on emerging data from the pandemic ${ }^{28,29}$, clinical experience ${ }^{30-33}$ and onsite activation of clinical trials (NCT04331808, NCT04341207 and NCT04333914). The oncological treatment strategy was adapted based on international and national guidelines, as previously summarized ${ }^{22}$.

Reporting Summary. Further information on research design is available in the Nature Research Reporting Summary linked to this article.

\section{Data availability}

The data underlying the findings of this study cannot be made freely available because of ethical and legal restrictions. This is because the present study includes an important number of variables that, together, could be used to re-identify the patients based on a few key characteristics. However, data from this study can be requested by filling out the data request form for Gustave Roussy clinical studies at https://redcap.gustaveroussy.fr/redcap/surveys/?s=DYDTLPE4AM. The process is similar for every study sponsored by Gustave Roussy. The study steering committee and the sponsor will review the requests on a case-by-case basis. In case of approval, a specific agreement between the sponsor and the researcher may be required for data transfer.

\section{Code availability}

SAS software version 9.4 was used for the analysis without customization. Statistical codes (SAS software) will be made available with the data if requested.

Received: 27 May 2020; Accepted: 24 August 2020;

Published online: 22 September 2020

\section{References}

1. Liang, W. et al. Cancer patients in SARS-CoV-2 infection: a nationwide analysis in China. Lancet Oncol. 21, 335-337 (2020).

2. Guan, W.-J. et al. Clinical characteristics of coronavirus disease 2019 in China. N. Engl. J. Med. 382, 1708-1720 (2020).

3. Grasselli, G. et al. Baseline characteristics and outcomes of 1591 patients infected with SARS-CoV-2 admitted to ICUs of the Lombardy region, Italy. J. Am. Med. Assoc. https://doi.org/10.1001/jama.2020.5394 (2020).

4. Simpson, S. et al. Radiological society of North America expert consensus statement on reporting chest CT Findings related to COVID-19. Endorsed by the society of thoracic radiology, the American College of Radiology, and RSNA. J. Thorac. Imag. https://doi.org/10.1097/RTI.0000000000000524 (2020).

5. Richardson, S. et al. Presenting characteristics, comorbidities, and outcomes among 5700 patients hospitalized with COVID-19 in the New York City area. J. Am. Med. Assoc. https://doi.org/10.1001/jama.2020.6775 (2020).

6. Williamson, E. J. et al. Factors associated with COVID-19-related death using OpenSAFELY. Nature https://doi.org/10.1038/s41586-020-2521-4 (2020).

7. Miyashita, H. et al. Do patients with cancer have a poorer prognosis of COVID-19? An experience in New York City. Ann. Oncol. Off. J. Eur. Soc. Med. Oncol. https://doi.org/10.1016/j.annonc.2020.04.006 (2020).

8. Dai, M. et al. Patients with cancer appear more vulnerable to SARS-COV-2: a multicenter study during the COVID-19 outbreak. Cancer Discov. https://doi. org/10.1158/2159-8290.CD-20-0422 (2020). 
9. Kuderer, N. M. et al. Clinical impact of COVID-19 on patients with cancer (CCC19): a cohort study. Lancet 395, 1907-1918 (2020).

10. Garassino, M. C. et al. COVID-19 in patients with thoracic malignancies (TERAVOLT): first results of an international, registry-based, cohort study. Lancet Oncol. 21, 914-922 (2020).

11. Mehta, V. et al. Case fatality rate of cancer patients with COVID-19 in a New York hospital system. Cancer Discov. https://doi.org/10.1158/2159-8290. CD-20-0516 (2020).

12. Luo, J. et al. Impact of PD-1 blockade on severity of COVID-19 in patients with lung cancers. Cancer Discov. https://doi.org/10.1158/2159-8290. CD-20-0596 (2020).

13. Lee, L. Y. W. et al. COVID-19 mortality in patients with cancer on chemotherapy or other anticancer treatments: a prospective cohort study. Lancet 395, 1919-1926 (2020).

14. Zhang, J.-J. et al. Clinical characteristics of 140 patients infected with SARS-CoV-2 in Wuhan, China. Allergy https://doi.org/10.1111/all.14238 (2020).

15. Tan, L. et al. Validation of predictors of disease severity and outcomes in COVID-19 patients: a descriptive and retrospective study. Med. https://doi. org/10.1016/j.medj.2020.05.002 (2020).

16. Ray-Coquard, I. et al. Lymphopenia as a prognostic factor for overall survival in advanced carcinomas, sarcomas, and lymphomas. Cancer Res. 69, 5383-5391 (2009).

17. Wen, W. et al. Immune cell profiling of COVID-19 patients in the recovery stage by single-cell sequencing. Cell Discov. 6, 31 (2020).

18. Zhou, Y. et al. Pathogenic T-cells and inflammatory monocytes incite inflammatory storms in severe COVID-19 patients. Natl Sci. Rev. https://doi. org/10.1093/nsr/nwaa041 (2020).

19. Merad, M. \& Martin, J. C. Pathological inflammation in patients with COVID-19: a key role for monocytes and macrophages. Nat. Rev. Immunol. https://doi.org/10.1038/s41577-020-0331-4 (2020).

20. Dinmohamed, A. G. et al. Fewer cancer diagnoses during the COVID-19 epidemic in the Netherlands. Lancet Oncol. https://doi.org/10.1016/ S1470-2045(20)30265-5 (2020).

21. Richards, M., Anderson, M., Carter, P., Ebert, B. L. \& Mossialos, E. The impact of the COVID-19 pandemic on cancer care. Nat. Cancer https://doi. org/10.1038/s43018-020-0074-y (2020).

22. Van de Haar, J. et al. Caring for patients with cancer in the COVID-19 era. Nat. Med. 26, 665-671 (2020).

23. Scotté, F. et al. A patient reported outcome platform, a useful tool to improve monitoring and effective management of COVID-19-positive patients with cancer. Eur. J. Cancer Oxf. Engl. 1990 132, 1-4 (2020).

24. COVID-19 Therapeutic Trial Synopsis (World Health Organization, 2020); https://www.who.int/publications-detail/covid-19-therapeutic-trial-synopsis

25. Harris, P. A. et al. Research electronic data capture (REDCap) - a metadata-driven methodology and workflow process for providing translational research informatics support. J. Biomed. Inform. 42, 377-381 (2009).

26. Harris, P. A. et al. The REDCap consortium: building an international community of software platform partners. J. Biomed. Inform. 95, 103208 (2019).

27. Corman, V. M. et al. Detection of 2019 novel coronavirus (2019-nCoV) by real-time RT-PCR. Euro Surveill. 25, 2000045 (2020).

28. Cao, B. et al. A trial of lopinavir-ritonavir in adults hospitalized with severe COVID-19. N. Engl. J. Med. 382, 1787-1799 (2020).

29. Wang, Y. et al. Remdesivir in adults with severe COVID-19: a randomised, double-blind, placebo-controlled, multicentre trial. Lancet 395, 1569-1578 (2020).

30. Michot, J.-M. et al. Tocilizumab, an anti-IL-6 receptor antibody, to treat Covid-19-related respiratory failure: a case report. Ann. Oncol. https://doi. org/10.1016/j.annonc.2020.03.300 (2020)

31. Gautret, P. et al. Hydroxychloroquine and azithromycin as a treatment of COVID-19: results of an open-label non-randomized clinical trial. Int. J. Antimicrob. Agents https://doi.org/10.1016/j.ijantimicag.2020.105949 (2020).

32. Million, M. et al. Early treatment of COVID-19 patients with hydroxychloroquine and azithromycin: A retrospective analysis of 1061 cases in Marseille, France. Travel Med. Infect. Dis. https://doi.org/10.1016/j. tmaid.2020.101738 (2020).

33. Russell, C. D., Millar, J. E. \& Baillie, J. K. Clinical evidence does not support corticosteroid treatment for 2019-nCoV lung injury. Lancet 395, 473-475 (2020).

34. Vuagnat, P. et al. COVID-19 in breast cancer patients: a cohort at the Institut Curie hospitals in the Paris area. Breast Cancer Res. 22, 55 (2020).

\section{Acknowledgements}

We thank the patients, their families and all of the investigators and caregivers involved in the COVID-19 pandemic management at the Gustave Roussy Cancer Centre. We also thank E. Gallois, T. Nihouarn, M. Wartelle, F. Lion, C. Mohamed-Djalim, G. Bescher, A. Pinto, H. Emerit, I. Sakraoui, L. Antoun, T. Grinda, C. Alves-Costa-Silva, L. Cerbone, J. C. Benitez-Montanez, S. Maillard, H. Bompais-Vincent and the Gustave Roussy
Clinical Research Department, as well as the ONCOVID clinical trial investigators and researchers. Part of this work was presented during the virtual Clinical Plenary Session at the AACR 2020 Annual Meeting on 28 April 2020.

\section{Author contributions}

L.A., S.F., A.B. and F.B. conceived of and designed the study. L.A., S.F., A.B., B.G., F.P., C.W., A.S., M.M., F.G., L.L., F.N., T.H., C.B., S.A., E.C., G.B., A.P., A.H., J.H., J.-M.M., N.C., V.S., M.H., J.-B.M., R.S., D.V.-C., F.A., F.S., B.B., J.-C.S. and F.B. collected and assembled the data and provided the patients. L.A., S.F., A.B. and F.B. analyzed and interpreted the data. L.A., S.F., A.B., B.G., F.P., C.W., A.S. M.M., F.G., L.L., F.N., T.H., C.B., S.A., E.C., G.B., A.P., A.H., J.H., J.-M.M., N.C., V.S., M.H., J.-B.M., R.S., D.V.-C., F.A., F.S., B.B., J.-C.S. and F.B. wrote the manuscript L.A., S.F., A.B., B.G., F.P., C.W., A.S., M.M., F.G., L.L., F.N., T.H., C.B., S.A., E.C., G.B., A.P., A.H., J.H., J.-M.M., N.C., V.S., M.H., J.-B.M., R.S., D.V.-C., F.A., F.S., B.B., J.-C.S. and F.B. gave final approval of the manuscript. L.A., S.F., A.B., B.G., F.P., C.W., A.S., M.M., F.G., L.L., F.N., T.H., C.B., S.A., E.C., G.B., A.P., A.H., J.H., J.-M.M., N.C., V.S., M.H., J.-B.M., R.S., D.V.-C., F.A., F.S., B.B., J.-C.S. and F.B. were accountable for all aspects of the work.

\section{Competing interests}

L.A. reports receiving consulting fees from Pfizer, Novartis, Bristol Myers Squibb, Ipsen, Roche, MSD, AstraZeneca, Merck, Amgen, Astellas, Exelixis, Corvus Pharmaceuticals and Peloton Therapeutics outside the submitted work. C.B. reports sponsorship for research from GE Healthcare and personal fees from Bracco. A.H. reports sponsorship for research at the Gustave Roussy Cancer Centre from AbbVie, Agios, Amgen, Astex, AstraZeneca, Bayer, BeiGene, Blueprint Medicines, Bristol Myers Squibb, Boehringer Ingelheim, Celgene, Chugai, Forma, Genentech, GlaxoSmithKline, H3 Biomedicine, Incyte, Innate Pharma, Janssen, Lilly, Loxo, MedImmune, MSD, Novartis, Oncopeptides, Roche, Sanofi, Taiho and Xencor outside the submitted work. J.-M.M. reports sponsorship for research at the Gustave Roussy Cancer Centre from AbbVie, Agios, Amgen, Astex, AstraZeneca, Bayer, BeiGene, Blueprint Medicines, Bristol Myers Squibb, Boehringer Ingelheim, Celgene, Chugai, Forma, Genentech, GlaxoSmithKline, H3 Biomedicine, Incyte, Innate Pharma, Janssen, Lilly, Loxo, MedImmune, MSD, Novartis, Oncopeptides, Roche, Sanofi, Taiho and Xencor outside the submitted work, as well as personal fees, travel grants or advisory board fees from Astex, iQone, Mundipharma and Bristol Myers Squibb outside the submitted work. J.-B.M. reports sponsorship for research at the Gustave Roussy Cancer Centre from H3 Biomedicine and personal fees, travel grants or advisory board fees from AbbVie, Novartis, Astellas and Jazz Pharmaceuticals outside the submitted work. R.S. reports grants from the ARC Foundation and Paris-Saclay University outside the submitted work. N.C. reports sponsorship for research at the Gustave Roussy Cancer Centre from the Bristol Myers Squibb Foundation, Sanofi, GlaxoSmithKline and Roche outside the submitted work, as well as personal fees, travel grants or advisory board fees from AstraZeneca, Bayer and Boehringer Ingelheim outside the submitted work. D.V.-C. reports receiving consulting fees from EUSA Pharma and sponsorship for research at the Gustave Roussy Cancer Centre from Orphelia outside the submitted work. F.A. reports receiving grants from Novartis, AstraZeneca, Pfizer, Lilly and Roche outside the submitted work. F.S. reports receiving personal fees from Helsinn, MSD, Roche, Amgen, Pierre Fabre Oncology, Pfizer, Mundipharma, Mylan and Leo Pharma outside the submitted work. B.B. reports sponsorship for research at the Gustave Roussy Cancer Centre from AbbVie, Amgen, AstraZeneca, BeiGene, Blueprint Medicines, Bristol Myers Squibb, Boehringer Ingelheim, Celgene, Cristal Therapeutics, Daiichi Sankyo, Eli Lilly, GlaxoSmithKline, Ignyta, IPSEN, Inivata, Janssen, Merck, MSD, Nektar, Onxeo, OSE Immunotherapeutics, Pfizer, Pharma Mar, Roche-Genentech, Sanofi, Servier, Spectrum Pharmaceuticals, Takeda, Tiziana Pharma and Tolero Pharmaceuticals outside the submitted work. J.-C.S reports receiving consultancy fees from AstraZeneca, Astex, Clovis, GlaxoSmithKline, GamaMabs, Lilly, MSD, Mission Therapeutics, Merus, Pfizer, Pharma Mar, Pierre Fabre, Roche-Genentech, Sanofi, Servier, Symphogen and Takeda; was a full-time employee for AstraZeneca between September 2017 and December 2019; and reports receiving other fees from the shareholder Gritstone during the conduct of the study. F.B. reports receiving personal fees from AstraZeneca, Bayer, Bristol Myers Squibb, Boehringer Ingelheim, Eli Lilly Oncology, F. Hoffmann-La Roche, Novartis, Merck, MSD, Pierre Fabre, Pfizer and Takeda outside the submitted work. S.F., A.B., B.G., F.P., C.W., A.S., M.M., F.G., L.L., F.N., T.H., S.A., E.C., G.B., A.P., J.H., V.S. and M.H. declare no competing interests.

\section{Additional information}

Extended data is available for this paper at https://doi.org/10.1038/s43018-020-00120-5. Supplementary information is available for this paper at https://doi.org/10.1038/ s43018-020-00120-5.

Correspondence and requests for materials should be addressed to F.B.

Reprints and permissions information is available at www.nature.com/reprints.

Publisher's note Springer Nature remains neutral with regard to jurisdictional claims in published maps and institutional affiliations.

(c) The Author(s), under exclusive licence to Springer Nature America, Inc. 2020 


\section{Treatment of Covid-19 infections}

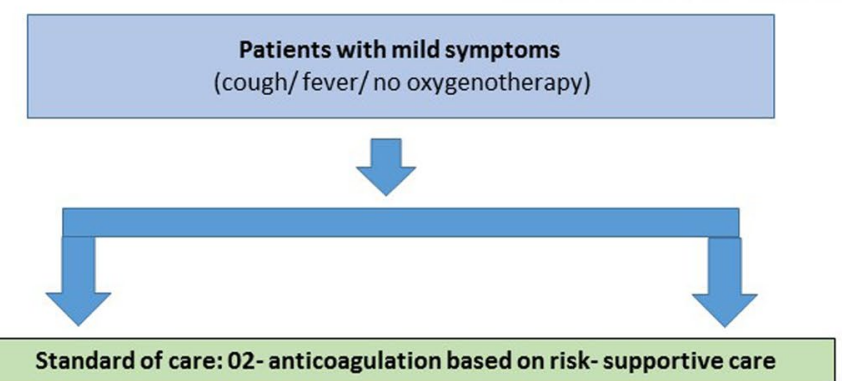

Standard of care: 02- anticoagulation based on risk- supportive care

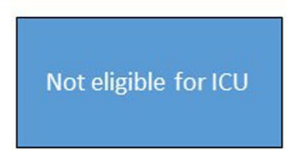

\begin{tabular}{|c|}
\hline IMMUNONCOVID \\
(NCTO4333914) \\
Cohort 1: \\
SOC vs \\
SOC + GNS 561 vs \\
SOC + NIVOLUMAB
\end{tabular}

Outside trial: $\mathrm{HCQ}+\mathrm{AZI}$ Or LOPI/RITO if $\mathrm{Cl}$ to $\mathrm{HCQ} / \mathrm{AZI}$

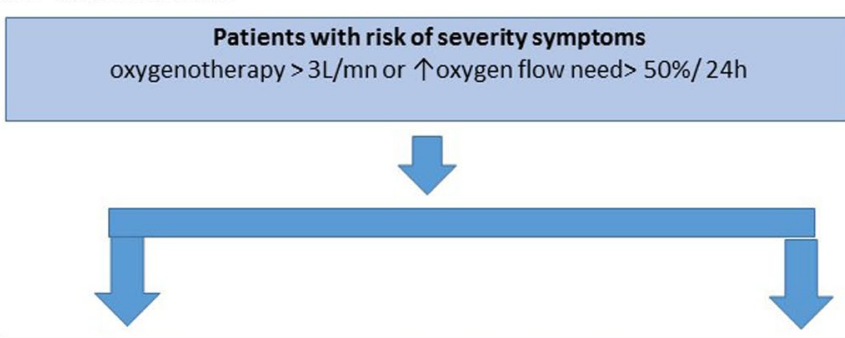

Standard of care: 02- anticoagulation based on risk- supportive care

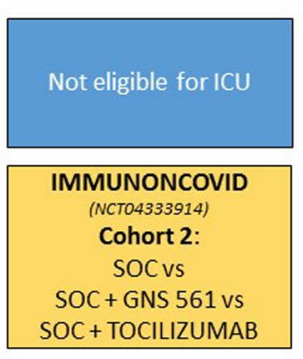

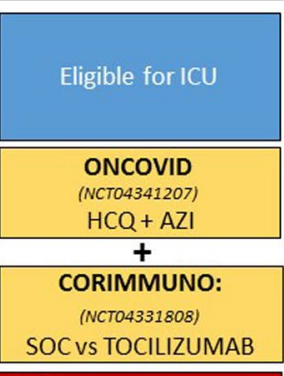

DEXAMETHASONE (Only after day 10)

Outside trial: $\mathrm{HCQ}+\mathrm{AZI}+$

DEXA or TOCl according to prognosis and $\mathrm{Cl}$

SOC: standard of care ; ICU: intensive care unit; HCQ : hydroxychloroquine; AZI : azithromycin;

DEXA : dexamethasone; TOCI : Tocilizumab ; LOPI : Lopinavir ; RITO : Ritonavir; $\mathrm{Cl}$ : contraindication

Extended Data Fig. 1 | Summary of COVID-19 treatments and symptom presentation. SOC, standard of care; ICU, intensive care unit HCQ, hydroxychloroquine; AZI, azithromycin; DEXA, dexamethasone; TOCI, tocilizumab; LOPI, Lopinavir; RITO, Ritonavir; Cl, contraindication. 


\section{Reporting Summary}

Nature Research wishes to improve the reproducibility of the work that we publish. This form provides structure for consistency and transparency in reporting. For further information on Nature Research policies, see our Editorial Policies and the Editorial Policy Checklist.

\section{Statistics}

For all statistical analyses, confirm that the following items are present in the figure legend, table legend, main text, or Methods section.

$\mathrm{n} / \mathrm{a}$ Confirmed

$\bigotimes$ The exact sample size $(n)$ for each experimental group/condition, given as a discrete number and unit of measurement

$\bigotimes$ A statement on whether measurements were taken from distinct samples or whether the same sample was measured repeatedly

The statistical test(s) used AND whether they are one- or two-sided

Only common tests should be described solely by name; describe more complex techniques in the Methods section.

$\bigotimes$ A description of all covariates tested

\A description of any assumptions or corrections, such as tests of normality and adjustment for multiple comparisons

A full description of the statistical parameters including central tendency (e.g. means) or other basic estimates (e.g. regression coefficient) AND variation (e.g. standard deviation) or associated estimates of uncertainty (e.g. confidence intervals)

For null hypothesis testing, the test statistic (e.g. $F, t, r$ ) with confidence intervals, effect sizes, degrees of freedom and $P$ value noted Give $P$ values as exact values whenever suitable.

Х $\square$ For Bayesian analysis, information on the choice of priors and Markov chain Monte Carlo settings

Х $\square$ For hierarchical and complex designs, identification of the appropriate level for tests and full reporting of outcomes

$\triangle \square$ Estimates of effect sizes (e.g. Cohen's d, Pearson's $r$ ), indicating how they were calculated

Our web collection on statistics for biologists contains articles on many of the points above.

\section{Software and code}

Policy information about availability of computer code

Data collection

Study data were collected and managed using REDCap ${ }^{\circledR}$ 9.8.4 (Research Electronic Data Capture) tools hosted at Gustave Roussy 
Descriptive statistics (number, percentages, median, interquartile range (IQR) and range) were used to describe population characteristics. The $\chi 2$ test (or Fisher test) and student test (or Wilcoxon test) were performed for inter-group comparisons, as appropriate. Time-to-event endpoints (clinical worsening-free survival and overall survival) were reported using the Kaplan-Meier method with Rothman's 95\% confidence intervals (Cl). For the study of clinical and biological prognostic factors, Cox's proportional hazard models were used to provide p-values and Hazard Ratios ) with associated $95 \% \mathrm{Cl}$ in both univariable 243 and multivariable analyses. The choice of variables to include in the multivariable analyses were driven by the number of events available (3-4 variables to include for 47 clinical worsenings/deaths and 31 deaths), the strength of the association in the univariable analyses and the absence of collinearity between variables included in the model (assessed by $x 2$ test and Fisher test for qualitative variables or Spearman correlation coefficients for quantitative variables). The assumption of proportional hazards was checked by testing the existence of an interaction between each variable and log(time) in each model. Due to the exploratory nature of the analyses, no formal adjustment for multiplicity was done. All tests were two-sided, and significance was accepted at the $5 \%$ level. The analyses were performed using SAS 9.4 software (SAS institute, Cary $\mathrm{NC)}$.

For manuscripts utilizing custom algorithms or software that are central to the research but not yet described in published literature, software must be made available to editors and

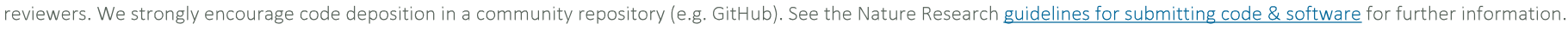

\section{Data}

Policy information about availability of data

All manuscripts must include a data availability statement. This statement should provide the following information, where applicable:

- Accession codes, unique identifiers, or web links for publicly available datasets

- A list of figures that have associated raw data

- A description of any restrictions on data availability

The data underlying the findings cannot be made freely available because of ethical and legal restrictions. This is because the present study includes an important number of variables that, together, could be used to re-identify the patients based on a few key characteristics. However, data from this study can be requested by filling out the data request form for Gustave Roussy clinical studies at:

https://redcap.gustaveroussy.fr/redcap/surveys/?s=DYDTLPE4AM.

The process is similar for every study sponsored by Gustave Roussy. The study steering committee and the sponsor will review the requests on a case-by-case basis. In case of approval, a specific agreement between the sponsor and the researcher may be required for data transfer. Statistical codes (SAS software) will be made available with the data, if requested.

\section{Field-specific reporting}

Please select the one below that is the best fit for your research. If you are not sure, read the appropriate sections before making your selection. \ Life sciences Behavioural \& social sciences Ecological, evolutionary \& environmental sciences

For a reference copy of the document with all sections, see nature.com/documents/nr-reporting-summary-flat.pdf

\section{Life sciences study design}

All studies must disclose on these points even when the disclosure is negative.

Sample size

In this retrospective study, no power analysis was done to calculate the sample size, and the aim was descriptive in nature. We used data from all the patients followed at Gustave Roussy and diagnosed COVID-19 between March 24th, 2020, until April 28th, 2020 corresponding to the peak of the epidemy in Paris area.

Data exclusions 209 patients were identified and the final study population included 178 adult patients, with the following exclusions: paediatric population (6) and non-cancer patients (19) or COVID-19 ultimately ruled out (6).

Replication

All the measurements were independently done in each patients (no repeated measurements).

Randomization

There was no randomization in this retrospective observationnal study.

Blinding

There was no bliding in this retrospective observationnal study. 


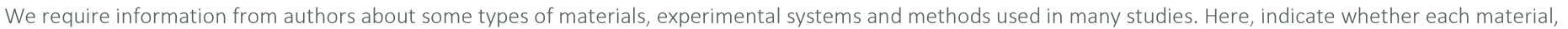

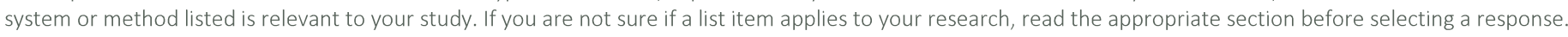

\begin{tabular}{|c|c|c|c|c|}
\hline \multicolumn{3}{|c|}{ Materials \& experimental systems } & \multicolumn{2}{|c|}{ Methods } \\
\hline $\mathrm{n} / \mathrm{a}$ & Inv & olved in the study & $\mathrm{n} / \mathrm{a}$ & Involved in the study \\
\hline Х & 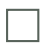 & Antibodies & Х & ChIP-seq \\
\hline Х & $\mathbf{L}^{-1}$ & Eukaryotic cell lines & Х & Flow cytometry \\
\hline Х & - & Palaeontology and archaeology & Х & MRI-based neuroimaging \\
\hline Х & ${ }^{-}$ & Animals and other organisms & & \\
\hline Х & $\mathbf{S}^{-1}$ & Human research participants & & \\
\hline & Х & Clinical data & & \\
\hline$\bigotimes$ & \begin{tabular}{|c|c} 
\\
\end{tabular} & Dual use research of concern & & \\
\hline
\end{tabular}

\section{Clinical data}

Policy information about clinical studies

All manuscripts should comply with the ICMJE guidelines for publication of clinical research and a completed CONSORT checklist must be included with all submissions.

Clinical trial registration In accordance with the French regulations, there was no requirement for ethics approval to be sought for this observational study, based on medical files. Conforming to GDPR and French law about clincal retrospective studies, patients included in our study have all received an information notice (non-opposal information) introducing study, following information included in article 14 of GDPR, and their rights about their data. This study was also declared to the Gustave Roussy's data protection officer on May 12th, 2020 then registered on the website of the Health Data French Institute, on May 20th, 2020 (declaration ${ }^{\circ}{ }^{\circ}$ MR4911200520).

Study protocol

A synopsis of the study protocol has been posted on the website of the Health Data French Institue (https://www.indsante.fr/fr/ repertoire-public/etudes-sous-mr)

Data collection

We performed a retrospective observational study to describe the management of adult patients with cancer (solid tumors or haematological malignancies) managed at Gustave Roussy after a diagnosis of SARS-Cov-2 (COVID-19) infection between March 14th, 2020 and April 29th, 2020. Study data were collected and managed using REDCap ${ }^{\circledR}$ 9.8.4 (Research Electronic Data Capture) tools hosted at Gustave Roussy

Outcomes

The aim of the study was to identify clinical and biological prognostic factors of clinical worsening and/or death.

Measures

Prognostic factors included demography (age, gender), comorbidities, solid tumor or haematological malignancies (tumour site, type, disease status, treatment received), and biological factors from lab tests at COVID-19 diagnosis. All the measurement were

independently done in each patient (no repeated measurements). Biological factors were categorized using pre-defined threshold values based on normal value cut-offs or recently published cut-offs in COVID-19. Chest CT imaging characteristics including extent of lung involvement at diagnosis were collected.

Outcomes

The outcomes studied were the clinical worsening-free survival (CWFS) and the overall survival (OS). CWFS was defined as the time from COVID-19 diagnosis to clinical worsening (oxygen needs $\geq 6 \mathrm{~L} / \mathrm{min}$ or admission to intensive care unit) or death. OS was defined as the time from COVID-19 diagnosis to death from any cause. 